\title{
Guideline on screening for esophageal adenocarcinoma in patients with chronic gastroesophageal reflux disease
}

\author{
Stéphane Groulx MD, Heather Limburg MSc, Marion Doull PhD, Scott Klarenbach MD MSc, Harminder Singh MD MPH, \\ Brenda J. Wilson MBChB MSc MRCP, Brett Thombs PhD; for the Canadian Task Force on Preventive Health Care
}

Cite as: CMAJ 2020 July 6;192:E768-77. doi: 10.1503/cmaj.190814

This guideline is available in French at www.cmaj.ca/lookup/suppl/doi:10.1503/cmaj.190814/-/DC1

CMAJ Podcasts: interview in English at https://soundcloud.com/cmajpodcasts/190814-guide; entrevue en français au https://soundcloud.com/cmajpodcasts/190814-guide-fre

See related article at www.cmaj.ca/lookup/doi/10.1503/cmaj.200697

n 2019, an estimated 6 new cases of esophageal cancer were diagnosed per 100000 Canadians. ${ }^{1}$ The 5 -year net survival rate, estimated at $15 \%$, is among the poorest of all cancer prognoses. ${ }^{1}$ Men have a higher incidence than women, with an estimated 9 cases versus 2 cases per 100000 , respectively. ${ }^{1}$ Adenocarcinoma is the most common type of esophageal cancer in Canada, followed by squamous cell carcinoma. ${ }^{2}$ Incidence has shifted over the past 40 years, with rates of adenocarcinoma increasing and squamous cell carcinoma falling (Figure 1 ). ${ }^{3}$ This change may have resulted from increases in adenocarcinoma-related risk factors (e.g., gastroesophageal reflux, obesity) and decreases in risk factors linked to squamous cell carcinoma (e.g., smoking). ${ }^{2}$ Thus, this guideline focuses on screening for esophageal adenocarcinoma.

The most important risk factors for esophageal adenocarcinoma are precancerous conditions (e.g., Barrett esophagus, esophageal dysplasia), older age ( $\geq 50 \mathrm{yr}$ ), gastroesophageal reflux disease (GERD), male sex, family history, white race or ethnicity, abdominal obesity and smoking. ${ }^{4-10}$

Gastroesophageal reflux disease (Montreal global definition ${ }^{11}$ ), is a common condition in which reflux of stomach contents (acid regurgitation) causes troublesome symptoms (e.g., heartburn, water brash). It should be distinguished from dyspepsia, which is a syndrome characterized predominantly by epigastric pain of at least 1-month duration. ${ }^{12}$ The prevalence of GERD (based on weekly symptoms) in North America and Europe is estimated at $10 \%$ to $20 \%$ of the population. ${ }^{13,14}$

Gastroesophageal reflux disease is associated with a 5 to 7 times increased likelihood of developing esophageal adenocarcinoma (35 v. 7 cases per 100000 men at age $60 \mathrm{yr}$ ); $60 \%$ of patients with this cancer report a history of GERD. ${ }^{15-17}$ Most people with chronic GERD, however, do not develop esophageal adenocarcinoma, and predicting progression remains difficult. ${ }^{18} \mathrm{~A}$ Markov model for white, non-Hispanic people at age 60 years who had at least weekly GERD symptoms estimated an esophageal

\section{KEY POINTS}

- The Canadian Task Force on Preventive Health Care recommends not screening adults with chronic gastroesophageal reflux disease (GERD) for esophageal adenocarcinoma and precursor conditions (Barrett esophagus or dysplasia), because there is an absence of evidence for benefit, and there are uncertain harms, important resource implications and variable patient values and preferences.

- A single retrospective cohort study (very low-certainty evidence) found that screening patients with chronic GERD identified more cases with esophageal adenocarcinoma at an early stage, but found no difference in long-term survival (all-cause mortality).

- Acceptability of screening was variable because of individual values and preferences; some people consistently favoured screening because of individual and familial risk factors, personal beliefs or fear of missing an early diagnosis, while others were concerned about the invasiveness and risks of screening.

- This guideline on screening does not apply to people exhibiting alarm symptoms that may be caused by esophageal adenocarcinoma (e.g., dysphagia, odynophagia, recurrent vomiting, unexplained weight loss, anemia, loss of appetite or gastrointestinal bleeding) or those diagnosed with Barrett esophagus (with or without dysplasia).

adenocarcinoma incidence of 35 per 100000 person-years for men and 4 per 100000 person-years for women. ${ }^{17}$

Barrett esophagus is a metaplastic adaptation of the esophageal cells in which intestinal-type mucosa replaces the normal squamous mucosa. ${ }^{19,20}$ About 5\% to $15 \%$ of patients with GERD develop Barrett esophagus, versus $1 \%$ to $2 \%$ of the general population. ${ }^{10}$ Dysplasia can occur independently but is more frequent in people with Barrett esophagus. ${ }^{21}$ The natural history of esophageal adenocarcinoma is believed to follow a sequential progression, from GERD to Barrett esophagus to low- and then high-grade dysplasia., ${ }^{5,22,23}$ Risk of developing esophageal adenocarcinoma from Barrett esophagus 


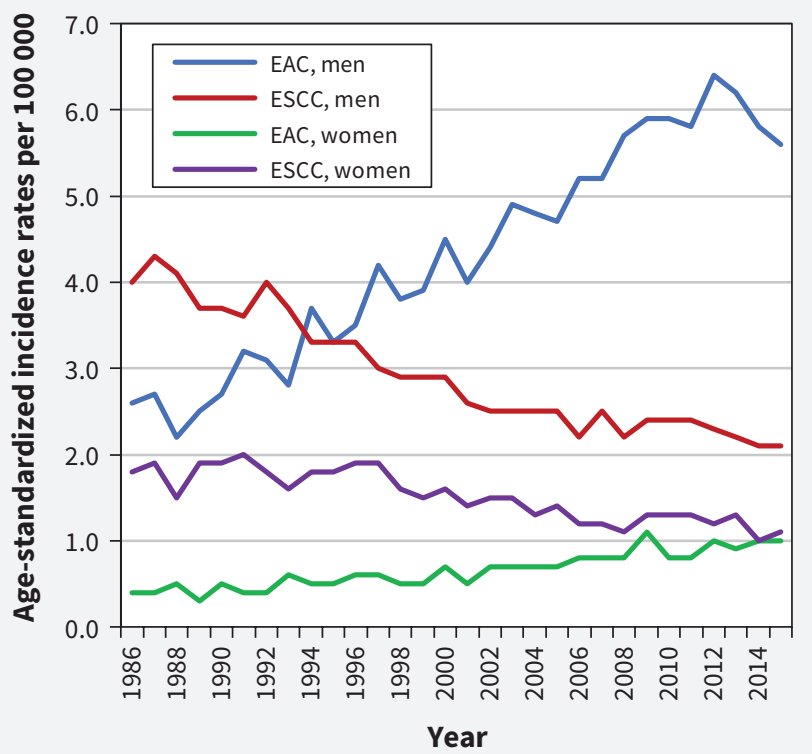

Figure 1: Age-standardized incidence rates ${ }^{*}$ for esophageal adenocarcinoma (EAC) and esophageal squamous cell carcinoma (ESCC), all ages, Canada (excluding Quebec), $† 1986$ to 2015. Data source: Canadian Cancer Registry and National Cancer Incidence Reporting System databases at Statistics Canada. Analysis by: Centre for Surveillance and Applied Research, Public Health Agency of Canada. Note: *Age standardized to the 2011 Canadian population; refer to Appendix $1 \mathrm{~F}$ for included esophageal cancer topography and morphology codes. †Data for Quebec were removed as they were not available for all time periods.

increases from an estimated $0.3 \%$ per year without dysplasia to $0.5 \%$ with low-grade dysplasia, and 6\% with high-grade dysplasia. ${ }^{24-26}$

About 93\% of diagnoses of esophageal adenocarcinoma are made while investigating patients with alarm symptoms, such as dysphagia, odynophagia, recurrent vomiting, unexplained weight loss, anemia, appetite loss or gastrointestinal bleeding, which can be associated with late-stage adenocarcinoma. ${ }^{7,27-29}$

The Canadian Task Force on Preventive Health Care investigated whether endoscopic screening of patients with chronic GERD without alarm symptoms would detect cancer at an earlier stage, detect precancerous treatable conditions (Barrett esophagus, dysplasia), reduce progression to esophageal adenocarcinoma, or decrease mortality.

\section{Scope}

This guideline's target audience is primary care practitioners, defined as health professionals who provide accessible, continued, comprehensive and coordinated care, and who are the first health system contact. ${ }^{30}$ The target population consists of adults with chronic GERD and excludes those with alarm symptoms or those given a diagnosis of Barrett esophagus (with or without dysplasia).

The task force initially defined chronic GERD as symptoms of GERD for 12 months or longer (with no specific frequency) or proton pump inhibitor (or other pharmacotherapy) use for GERD for 12 months or longer. ${ }^{31,32}$ However, we later expanded the definition to allow for inclusion in the evidence review for the guideline any study on "chronic GERD" based on the criteria used by the author. ${ }^{33-35}$

\section{Recommendation}

We recommend not screening adults ( $\geq 18$ years) with chronic GERD for esophageal adenocarcinoma or precursor conditions (Barrett esophagus or dysplasia) (strong recommendation; very low-certainty evidence).

This recommendation does not apply to people exhibiting alarm symptoms or those given a diagnosis of Barrett esophagus (with or without dysplasia).

Although risk factors such as age ( $\geq 50 \mathrm{yr}$ ), male sex, family history, white race or ethnicity, abdominal obesity and smoking may increase the risk for esophageal adenocarcinoma, relevant trials and cohort studies did not include sufficient data within each category to support modifying our screening recommendation based on these factors, alone or in combination (Appendix $1 \mathrm{C}$, available at www.cmaj.ca/lookup/suppl/doi:10.1503/cmaj.190814/-/ DC2). ${ }^{33,35}$ See Box 1 for definitions of certainty of evidence and recommendation strength used in task force guidelines. ${ }^{36}$

\section{Screening}

A systematic review found 2 retrospective cohort studies, based on electronic medical records, that assessed the effectiveness (benefits and harms) of screening versus no screening among patients with chronic GERD. ${ }^{39,40}$ The severity or duration of GERD was not defined in either study. Rubenstein and colleagues reported on 155 patients who were given a diagnosis of esophageal adenocarcinoma and who did $(n=25)$ or did not $(n=130)$ receive esophagogastroduodenoscopy in the previous 5 years. In terms of potential benefits, this study found no statistically significant improvement in long-term survival (all-cause mortality) (adjusted hazard ratio [HR] 0.93, 95\% confidence interval [Cl] 0.58 to 1.50 ) (very low-certainty evidence)..$^{39}$ The same study showed a statistically significant absolute effect of 156 more per 1000 (95\% Cl, 5 to 486 more per 1000) given a diagnosis of a lower stage of esophageal adenocarcinoma (stage $1 \mathrm{v}$. stages 2-4) among those with previous esophagogastroduodenoscopy (very low-certainty evidence) (Table 1 ). The second retrospective cohort study had insufficient data to determine whether screening reduces stage at diagnosis or mortality. ${ }^{40}$ Both studies presented insufficient data to permit subgroup analyses by risk factors (Appendix 1C). ${ }^{33,35}$ No included studies reported or provided data on other identified outcomes of interest (i.e., cause-specific mortality, quality of life, additional medical procedures or overdiagnosis). ${ }^{33,35}$ Five randomized controlled trials (RCTs) ${ }^{41-45}$ and 1 cohort study ${ }^{46}$ compared different screening modalities for Barrett esophagus, including sedated esophagogastroduodenoscopy, unsedated transnasal esophagoscopy, video capsule esophagoscopy (swallowed) and unsedated transoral esophagoscopy. ${ }^{33,35}$ When reported, the definition of GERD varied among studies; some did not report duration of GERD ${ }^{42,45,46}$ or proton pump inhibitor use; ;2,45 and none used the Montreal global definition. ${ }^{11}$ There were no statistically significant differences in detection rates of confirmed Barrett esophagus or dysplasia among modalities, and no cases of esophageal adenocarcinoma were found (very low-certainty evidence). ${ }^{33,35}$ 


\section{Box 1: Grading of recommendations ${ }^{36}$}

Recommendations are graded according to the Grading of Recommendations Assessment, Development and Evaluation system (GRADE). ${ }^{37}$ Whether a recommendation is strong or conditional ${ }^{*}$ will depend on considerations such as certainty in estimated effects of an intervention, including magnitude, as well as estimates of how patients value and prioritize outcomes, variability of these estimates and wise use of resources.

\section{Strong recommendations}

Strong recommendations are those for which the Canadian Task Force on Preventive Health Care is confident that the desirable effects of an intervention outweigh its undesirable effects (strong recommendation for an intervention) or that the undesirable effects of an intervention outweigh its desirable effects (strong recommendation against an intervention). A strong recommendation implies that most people will be best served by the recommended course of action.

Strong recommendations are typically based on high-certainty evidence (i.e., high confidence in the estimate of the effect of an intervention). Strong recommendations may recommend in favour of an intervention (when there is high confidence of net benefit) or against an intervention (when there is high confidence of net harm). However, there are circumstances in which a strong recommendation may be considered based on low- or very low-certainty evidence or when there is absence of evidence or low-certainty evidence of benefit.

When there is an absence of evidence to provide confidence that there is benefit from implementing a new prevention service or when a conclusion of possible benefit requires a high level of speculation on linkages of uncertain evidence, but there is high certainty that some patients would be harmed or scarce health care resources expended, the task force may make a strong recommendation against service implementation. This is consistent with the GRADE approach, ${ }^{38}$ in which strong recommendations are sometimes made with low-certainty evidence combined with high certainty of harm or resource implications, and with the value that the task force places on using scarce primary care resources wisely.

\section{Conditional recommendations}

Conditional recommendations are those for which the desirable effects probably outweigh the undesirable effects (conditional recommendation in favour of an intervention) or undesirable effects probably outweigh the desirable effects (conditional recommendation against an intervention) but appreciable uncertainty exists. Conditional recommendations are made when the certainty of evidence is lower, when the margin between desirable and undesirable consequences is small and the balance depends on patient values and preferences, or when there is high variability in the values and preferences of patients. Conditional recommendations may also be applied when the balance of cost and benefits is ambiguous, key stakeholders differ about the acceptability or feasibility of the implementation, or the effects on health equity are unclear.

In certain cases where a conditional recommendation for an intervention is made, clinicians are encouraged to engage in shared decision-making, to recognize that different choices will be appropriate for individual patients, and to help each person arrive at a management decision consistent with their values and preferences. This requires clinicians to recognize that different choices will be appropriate for different patients and that decisions must be consistent with each patient's values and preferences. Knowledge translation tools are available on the task force website (www.canadiantaskforce.ca) to facilitate decisions that are evidence informed and aligned with an individual's priorities.

Evidence is rated as high-, moderate-, low- or very low-certainty, based on how likely further research is to change the task force's confidence in the estimate of effect.

*The task force previously used the term "weak recommendation," but has replaced this with the term "conditional recommendation," to improve understanding and facilitate implementation of guidance, based on feedback from clinician knowledge users. One reason for this change was the value that the task force places on shared decision-making, together with a need to clarify better when implementation of a recommendation depends on circumstances such as patient values, resource availability or other contextual considerations.
Harms of screening were evaluated in 4 RCTs. ${ }^{41,43-45}$ Evidence from 2 trials comparing sedated esophagogastroduodenoscopy versus unsedated transnasal esophagoscopy $(n=209)^{43}$ and unsedated transnasal versus unsedated transoral esophagogastroduodenoscopy $(n=59)^{45}$ reported 1 serious adverse event (after transnasal endoscopy). ${ }^{33,35}$ In 3 RCTs, unsedated transnasal esophagoscopy was associated with statistically significant higher anxiety (harm) compared with sedated esophagogastroduodenoscopy (during the procedure) or video capsule esophagoscopy (before and during procedure) (very low-certainty evidence) ${ }^{41,43,44}$ (Table 2). However, the mild additional discomfort seemed to be well tolerated, given that $70 \%$ to $95 \%$ of participants stated they would undergo it again. ${ }^{41-45}$

\section{Treatment}

Given the limited availability of direct evidence on screening effectiveness, the task force also examined indirect evidence on the effectiveness of treatment for Barrett esophagus, dysplasia or stage 1 esophageal adenocarcinoma. ${ }^{35,47}$ This evaluation focused on endoscopic treatment approaches, which are most relevant to screen-detected cancers (i.e., early stage); esophagectomy is standard care for localized esophageal cancer that has progressed beyond very early stages. ${ }^{5,48}$

In terms of potential treatment benefit, results show that photodynamic therapy, radiofrequency ablation and endoscopic mucosal resection of Barrett esophagus (with or without proton pump inhibitors) provide a statistically significant increase in eradication or clearance of dysplasia (very low- to low-certainty evidence) (Appendix 1D). ${ }^{35,47}$ Possible reduction in progression to esophageal adenocarcinoma was also observed with photodynamic therapy (very low- to low-certainty evidence). ${ }^{35,47}$ Mortality results were very limited (event rates of 0 to 3 per trial). ${ }^{35,47}$ Across outcomes, very low- to low-certainty evidence supports that these treatments improve eradication or clearance of dysplasia but the benefit is unknown for mortality.

Evaluation of treatment complications found a statistically significant increase in stenosis and strictures for endoscopic mucosal resection compared with radiofrequency ablation (very low-certainty evidence) (Appendix 1E). ${ }^{35,47} \mathrm{~A}$ statistically significant increase in stricture formation occurred with photodynamic therapy plus omeprazole compared with omeprazole alone (very low-certainty evidence). ${ }^{35,47}$ No data were reported on other identified outcomes of interest (quality of life, psychological effects of treatment, additional medical procedures after treatment or overdiagnosis). ${ }^{35,47}$

\section{Patient values and preferences}

A systematic review of patient values and preferences ${ }^{34,35}$ found no evidence on how patients weigh the benefits and harms of screening. However, evidence on factors that contribute to willingness to be screened (acceptability) was found in 3 studies comparing endoscopic screening 
strategies (unsedated transnasal esophagoscopy, ${ }^{41,45}$ video capsule esophagoscopy [swallowed], ${ }^{41}$ unsedated peroral endoscopy ${ }^{45,49}$ and sedated endoscopy). ${ }^{49}$ In 1 trial, among 1210 invited participants, $52 \%$ did not respond to the letter, $32 \%$ declined screening (no reason provided), $1 \%$ were ineligible and $0.2 \%$ cited difficulty attending. ${ }^{41}$ Two other studies had high "stated or intended" refusal rates (45/105 patients, 43\%; 19/62 patients, 31\%), from anxiety, lack of interest, fear of gagging, unwillingness to be study participants, or reluctance to undergo transnasal procedures. ${ }^{45,49}$

Surveys and focus groups conducted by the knowledge translation team in support of this guideline reported that when considering harms relative to benefits, participants with chronic GERD had a moderate desire to be screened (median rating $=6$ out of 9 , with $1=$ not at all willing and 9 = very much willing). ${ }^{50}$ For many of these respondents, individual or familial risk factors, personal beliefs or fear of missing an early diagnosis outweighed concerns about screening (e.g., invasiveness and complications). For some, the low certainty of evidence and perceived risk of screening would have led to a decision not to be screened. ${ }^{50}$ Based on this range of observations from trials and within focus groups, values and preferences for screening are judged to be variable.

\section{Resource use}

Because of very low certainty and lack of evidence showing benefit from screening, no economic evaluation or systematic review of cost-effectiveness was conducted. Potential costs of screening include physician services, hospital and facility expenses, and biopsy analyses..$^{51,52}$

\section{Feasibility, acceptability, cost and equity}

In the judgment of the task force, there are important feasibility and cost concerns, given that chronic GERD is a very common condition (10\%-20\% of Canadians). ${ }^{13,14}$ Canadian reports show that endoscopy wait times are perceived as too long and exceed recommended targets. ${ }^{53,54}$ Implementing screening would increase demand and could adversely affect health equity, as recent immigrant, rural or remote, Indigenous or lowincome populations may not have equal access. ${ }^{55,56}$ Given the limited and uncertain evidence of effectiveness, we believe screening all patients with GERD would not be feasible or acceptable and that it could inappropriately divert substantial health care resources.

\section{Rationale}

The overall certainty of evidence was very low. One small retrospective cohort study compared screening to no screening and reported that, although patients with a previous esophagogastroduodenoscopy were statistically more likely to have a lower stage of adenocarcinoma at the time of diagnosis, there were no statistically significant survival differences (i.e., no benefit). ${ }^{39}$ One serious adverse event from screening was reported across 2 small trials, which compared screening modalities (very lowcertainty evidence). ${ }^{33,35}$ Values and preferences of patients were variable, as some indicated a moderate willingness to be screened (based on their judgment of the benefits and harms); $;^{50}$ however, actual participation in screening trials was low..$^{34,35}$ Additionally, screening all adults with chronic GERD would require substantial resources.

Some endoscopic treatments may eradicate dysplasia, but the overview of reviews for this indirect evidence showed a range of possible evidence certainty from very low to low. ${ }^{35,47}$ Effectiveness of medical treatment for Barrett esophagus needs to be confirmed.

Because we identified only a statistically significant earlier stage at diagnosis (in 1 retrospective cohort study ${ }^{39}$ ), without a difference in survival or other patient important outcomes, the

Table 1: Outcome summary of screening versus no screening for esophageal adenocarcinoma among individuals with chronic gastroesophageal reflux disease

\begin{tabular}{|c|c|c|c|c|c|c|c|}
\hline Outcome & $\begin{array}{c}\text { No. and design } \\
\text { of studies }\end{array}$ & Screened & Not screened & $\begin{array}{l}\text { Risk ratio } \\
(95 \% \mathrm{Cl})\end{array}$ & $\begin{array}{c}\text { Absolute } \\
\text { difference per } 1000 \\
(95 \% \mathrm{Cl})\end{array}$ & $\begin{array}{c}\text { Absolute } \\
\text { increase, } \%\end{array}$ & $\begin{array}{l}\text { Certainty of } \\
\text { evidence }\end{array}$ \\
\hline $\begin{array}{l}\text { Stage } 1 \text { at } \\
\text { diagnosis }\end{array}$ & $\begin{array}{c}1 \text { retrospective } \\
\text { cohort } \\
\text { (Hammad et al., } \\
2019)^{40}\end{array}$ & \multicolumn{5}{|c|}{$\begin{array}{l}\text { Narrative summary: } 1 \text { out of } 153 \text { patients, not under surveillance for Barrett esophagus, had } \\
\text { received an EGD in the previous } 5 \text { years. An additional } 15 \text { had received an EGD }>5 \text { years ago, } \\
\text { with no additional details on timing. For the purposes of this review, these patients were } \\
\text { grouped with those with no previous EGD. This } 1 \text { "screened" patient was diagnosed with } \\
\text { "unknown stage" of esophageal adenocarcinoma. }\end{array}$} & Very low* \\
\hline
\end{tabular}

Note: $\mathrm{Cl}$ = confidence interval, $\mathrm{EGD}=$ esophagogastroduodenoscopy, $\mathrm{GRADE}=$ Grading of Recommendations Assessment, Development and Evaluation, $\mathrm{HR}=$ hazard ratio ${ }^{*} A$ GRADE assessment of very low certainty was given because the risk of bias, indirectness and imprecision was rated as serious. 
Table 2: Outcome summary of harms before and during screening for esophageal adenocarcinoma among individuals with chronic gastroesophageal reflux disease (by screening modality)

\begin{tabular}{|c|c|c|c|c|c|c|c|}
\hline \multirow{3}{*}{$\begin{array}{l}\text { Outcome } \\
\text { Life-threatening, } \\
\text { severe or } \\
\text { medically } \\
\text { significant } \\
\text { consequences }\end{array}$} & \multirow{2}{*}{$\begin{array}{l}\text { No. and design } \\
\text { of studies } \\
1 \text { RCT (Sami et } \\
\text { al., 2015) }\end{array}$} & \multicolumn{2}{|c|}{ Screening modality } & $\begin{array}{l}\text { Risk ratio } \\
(95 \% \mathrm{CI})\end{array}$ & $\begin{array}{l}\text { Absolute } \\
\text { difference per } 1000 \\
(95 \% \mathrm{Cl})\end{array}$ & $\begin{array}{l}\text { Absolute } \\
\quad \text { risk } \\
\text { increase, } \%\end{array}$ & \multirow{2}{*}{$\begin{array}{l}\begin{array}{l}\text { Certaint } \\
\text { of eviden }\end{array} \\
\text { Very low' }\end{array}$} \\
\hline & & $\begin{array}{l}\text { Standard sedated } \\
\text { EGD: } 0 / 61\end{array}$ & $\begin{array}{l}\text { Unsedated TNE:* } \\
0 / 148\end{array}$ & \multicolumn{3}{|c|}{$\begin{array}{l}\text { Narrative summary: Not estimable, owing to } 0 \text { count } \\
\text { in both arms (serious adverse events were assessed } 1 \\
\text { and } 30 \text { days after the procedure). }\end{array}$} & \\
\hline & $\begin{array}{l}1 \text { RCT (Zaman } \\
\text { et al., 1999) }\end{array}$ & $\begin{array}{l}\text { Unsedated } \\
\text { transoral EGD: } \\
0 / 34\end{array}$ & $\begin{array}{l}\text { Unsedated TNE: } \\
1 / 25\end{array}$ & \multicolumn{3}{|c|}{$\begin{array}{l}\text { Narrative summary: Not estimable, owing to } 0 \text { count } \\
\text { in comparison group. }\end{array}$} & Very low $\ddagger$ \\
\hline \multirow[t]{3}{*}{$\begin{array}{l}\text { Anxiety before } \\
\text { the procedure }\end{array}$} & $\begin{array}{l}1 \text { RCT } \\
\text { (Chak et al., } \\
2014)^{41}\end{array}$ & $\begin{array}{l}\text { Unsedated TNE: } \\
33 / 87\end{array}$ & $\begin{array}{l}\text { VCE (swallowed } \\
\text { device): } 15 / 90\end{array}$ & $\begin{array}{c}2.28 \\
(1.33-3.88)\end{array}$ & $\begin{array}{l}213 \text { per } 1000 \text { more } \\
\text { experience anxiety } \\
\text { with unsedated TNE } \\
\text { ( } 55 \text { more to } 480 \\
\text { more) }\end{array}$ & 21.3 & Very low \\
\hline & $\begin{array}{l}1 \text { RCT } \\
\text { (Jobe et al., } \\
2006)^{44}\end{array}$ & $\begin{array}{l}\text { Standard sedated } \\
\text { EGD: } \\
\text { None: } 64 / 116 \\
\text { Mild: } 26 / 116 \\
\text { Moderate: } 16 / 116 \\
\text { Severe: } 10 / 116\end{array}$ & $\begin{array}{l}\text { Unsedated TNE: } \\
\text { None: } 59 / 116 \\
\text { Mild: } 39 / 116 \\
\text { Moderate: } 13 / 116 \\
\text { Severe: } 5 / 116\end{array}$ & \multicolumn{3}{|c|}{$\begin{array}{l}\text { Narrative summary: Authors reported those who } \\
\text { experienced no anxiety and mild, moderate and } \\
\text { severe anxiety. There was no statstically significant } \\
\text { difference between screening modalities }(p=0.08) \text {. }\end{array}$} & Very low $†$ \\
\hline & $\begin{array}{c}1 \text { RCT } \\
\text { (Zaman et al., } \\
1999)^{45}\end{array}$ & $\begin{array}{l}\text { Unsedated TNE: } \\
\text { Mean } \pm \text { SE } \\
3.0 \pm 0.6\end{array}$ & $\begin{array}{l}\text { Unsedated } \\
\text { transoral EGD: } \\
\text { Mean } \pm \text { SE } \\
3.0 \pm 0.5\end{array}$ & \multicolumn{3}{|c|}{$\begin{array}{l}\text { Narrative summary: Authors reported mean anxiety } \\
\text { before the procedure. There was no statistically } \\
\text { significant difference between screening modalities } \\
(p=0.39) \text {. }\end{array}$} & Very low $†$ \\
\hline \multirow[t]{2}{*}{$\begin{array}{l}\text { Anxiety during } \\
\text { insertion }\end{array}$} & $\begin{array}{l}1 \text { RCT } \\
\text { (Jobe et al., } \\
2006)^{44}\end{array}$ & $\begin{array}{l}\text { Standard sedated } \\
\text { EGD: } \\
\text { None: } 83 / 116 \\
\text { Mild: } 15 / 116 \\
\text { Moderate: } 7 / 116 \\
\text { Severe: } 11 / 116\end{array}$ & $\begin{array}{l}\text { Unsedated TNE: } \\
\text { None: } 45 / 116 \\
\text { Mild: } 43 / 116 \\
\text { Moderate: } 19 / 116 \\
\text { Severe: } 9 / 116\end{array}$ & \multicolumn{3}{|c|}{$\begin{array}{l}\text { Narrative summary: Authors reported those who } \\
\text { experienced no anxiety, and mild, moderate and } \\
\text { severe anxiety. There was a statistically significant } \\
\text { difference between modalities }(p<0.01) \text {, with those } \\
\text { randomized to unsedated TNE experiencing more } \\
\text { anxiety during insertion. }\end{array}$} & Very low $†$ \\
\hline & $\begin{array}{c}1 \text { RCT } \\
\text { (Zaman et al., } \\
1999)^{45}\end{array}$ & $\begin{array}{l}\text { Unsedated TNE: } \\
\text { Mean } \pm \text { SE } \\
4.4 \pm 0.6\end{array}$ & $\begin{array}{l}\text { Unsedated } \\
\text { transoral EGD: } \\
\text { Mean } \pm \text { SE } \\
4.7 \pm 0.5\end{array}$ & \multicolumn{3}{|c|}{$\begin{array}{l}\text { Narrative summary: Authors reported mean anxiety } \\
\text { during insertion. There was no statistically significant } \\
\text { difference between screening modalities ( } p=0.63 \text { ). }\end{array}$} & Very low $†$ \\
\hline $\begin{array}{l}\text { Anxiety during } \\
\text { the procedure }\end{array}$ & $\begin{array}{c}1 \text { RCT } \\
\text { (Chak et al., } \\
2014)^{41}\end{array}$ & $\begin{array}{l}\text { Unsedated TNE: } \\
29 / 87\end{array}$ & $\begin{array}{l}\text { VCE (swallowed } \\
\text { device): } \\
14 / 90\end{array}$ & $\begin{array}{c}2.14 \\
(1.22-3.77)\end{array}$ & $\begin{array}{l}177 \text { per } 1000 \text { more } \\
\text { experienced anxiety } \\
\text { with unsedated TNE } \\
\text { ( } 34 \text { more to } 431 \\
\text { more) }\end{array}$ & 17.7 & Very low $\dagger$ \\
\hline
\end{tabular}

\begin{tabular}{|c|c|c|}
\hline $\begin{array}{c}1 \mathrm{RCT} \\
\text { (Sami et al., } \\
2015)^{43}\end{array}$ & $\begin{array}{l}\text { Standard sedated } \\
\text { EGD: } \\
\text { Mean } \pm \text { SD } \\
0.8 \pm 1.5\end{array}$ & $\begin{array}{l}\text { Unsedated TNE: } \\
\text { Mean } \pm \text { SD } \\
\text { Hospital TNE: } 2.3 \pm \\
2.2 \\
\text { Mobile TNE: } \\
2.8 \pm 2.8\end{array}$ \\
\hline $\begin{array}{c}1 \text { RCT } \\
\text { (Jobe et al., } \\
2006)^{44}\end{array}$ & $\begin{array}{l}\text { Standard sedated } \\
\text { EGD: } \\
\text { None: } 87 / 116 \\
\text { Mild: } 11 / 116 \\
\text { Moderate: } 11 / 116 \\
\text { Severe: } 7 / 116\end{array}$ & $\begin{array}{l}\text { Unsedated TNE: } \\
\text { None: } 62 / 116 \\
\text { Mild: } 38 / 116 \\
\text { Moderate: } 12 / 116 \\
\text { Severe: } 4 / 116\end{array}$ \\
\hline $\begin{array}{c}1 \mathrm{RCT} \\
\text { Zaman et al., } \\
1999)^{45}\end{array}$ & $\begin{array}{l}\text { Unsedated TNE: } \\
\text { Mean } \pm \text { SE } \\
3.3 \pm 0.7\end{array}$ & $\begin{array}{l}\text { Unsedated } \\
\text { transoral EGD: } \\
\text { Mean } \pm \text { SE } \\
3.3 \pm 0.5\end{array}$ \\
\hline
\end{tabular}

Narrative summary: Authors reported the results using means on a scale of $0-10$, where 10 is severe. There were statistically significant differences between modalities, with those randomized to unsedated TNE experiencing more anxiety during the procedure $(p<0.01)$.

Narrative summary: Authors reported the results using the number of participants who selected the level of anxiety as "none," "mild," "moderate" and "severe." There were statistically significant differences between modalities, with those randomized to unsedated TNE experiencing more anxiety during the procedure $(p<0.01)$.

Narrative summary: Authors reported mean anxiety during the procedure. The mean anxiety during the procedure did not differ between the unsedated TNE group and the unsedated transoral EGD group $(p=0.99)$.

Very low†

Very low ${ }^{\dagger}$

Very low $\dagger$ Mean \pm SE

Note: $\mathrm{Cl}$ = confidence interval, EGD = esophagogastroduodenoscopy, GERD = gastroesophageal reflux disease, GRADE = Grading of Recommendations Assessment, Development and Evaluation, RCT = randomized controlled trial, $\mathrm{SD}=$ standard deviation, $\mathrm{SE}=$ standard error, $\mathrm{TNE}=$ transnasal esophagoscopy, $\mathrm{VCE}=$ video capsule esophagoscopy . *Unsedated TNE combines 0/72 (hospital TNE) and 0/76 (mobile TNE).

TA GRADE assessment of very low certainty was given because the risk of bias was rated as very serious. In addition, indirectness and imprecision were rated as serious.

ҒA GRADE assessment of very low certainty was given because the risk of bias, indirectness and imprecision were rated as serious. 
task force recommends against screening. The recommendation is strong because in its evidence-to-decision framework, the task force placed a high value on the system-wide resources required to screen all patients with chronic GERD without evidence of benefit (Appendix 1B). As referenced in a previous guideline, ${ }^{36}$ "when there is an absence of evidence to provide confidence that there is benefit from implementing a new prevention service and there is high certainty that scarce health care resources would be expended, the task force may make a strong recommendation against service implementation. This is consistent with the GRADE approach, ${ }^{38}$ in which strong recommendations are sometimes made with low-certainty evidence combined with high certainty of harm or resource implications, and with the value that the task force places on using primary care resources wisely."

\section{Methods}

The Canadian Task Force on Preventive Health Care is an independent panel of clinicians and methodologists that makes recommendations on primary and secondary prevention in primary care (www.canadiantaskforce.ca). This guideline was developed by a working group of 5 task force members with scientific support from the Public Health Agency of Canada.

The analytic framework for the guideline, including key questions, is available in Appendix 1A. We selected outcomes rated as critical or important by patients (see below) or task force members to inform the systematic reviews and recommendation. Ultimately, there were 3 critical outcomes selected: all-cause mortality, cancer-related mortality and life-threatening severe or medically significant complications of screening; and 5 important outcomes selected: incidence of esophageal adenocarcinoma (by stage), quality of life, psychological effects, additional major and minor medical procedures, and overdiagnosis.

The recommendation in this guideline was informed by systematic reviews on the effectiveness of screening ${ }^{33,35}$ and patient preferences and values, ${ }^{34,35}$ and an overview of systematic reviews on treatment effectiveness, ${ }^{35,47}$ all of which are available at www.canadiantaskforce.ca/guidelines/published-guidelines/ esophageal-adenocarcinoma/. Analysis of patient focus group results ${ }^{50,57}$ also informed the recommendation.

The Evidence Review and Synthesis Centre at the Ottawa Hospital Research Institute conducted the 2 systematic reviews ${ }^{33-35}$ and the overview of systematic reviews ${ }^{35,47}$ between September 2016 and June 2018; prepublication search updates were conducted in October ${ }^{33-35}$ and November 2018..$^{35,47}$ The protocols were registered on PROSPERO (CRD42017049993; CRD42017050014; CRD42018084825) and are available at www. canadiantaskforce.ca/guidelines/published-guidelines/esophageal -adenocarcinoma/. ${ }^{31,32,58}$

The task force used the Grading of Recommendations, Assessment, Development and Evaluation (GRADE) approach to determine certainty of evidence and strength of recommendations (Box 1). ${ }^{37}$ Appendix 1B provides the GRADE evidence-to-decision framework for the recommendations, which the entire task force reviewed and approved.

\section{Patient engagement}

The task force engaged patients in guideline development through 2 phases conducted by the Knowledge Translation group at St. Michael's Hospital, Toronto. ${ }^{50,57}$ Each phase recruited 17 men and women (aged $\geq 18 \mathrm{yr}$ ) with chronic GERD. Phase 1 consisted of online surveys and telephone focus groups, and obtained patient ratings of various clinical outcomes (benefits and harms) of screening. Phase 2 asked participants to reconsider outcome ratings when presented with synthesized evidence from the systematic reviews.

\section{External and content expert review}

External stakeholders and clinical and content experts reviewed the protocols, ${ }^{31,32}$ systematic reviews, ${ }^{33,34}$ overview of systematic reviews ${ }^{47}$ and draft guideline. Clinical and content experts engaged with task force working group members to help them address technical and clinical considerations, by participating in working group meetings, reviewing key supporting documents for accuracy and by reviewing the final guideline. These experts are external to the task force and do not vote on recommendations.

\section{Management of competing interests}

Funding for the task force is provided by the Public Health Agency of Canada. The task force does not consider the views of the funding body in developing its recommendations. All task force members are required to disclose financial and nonfinancial competing interests. These are made available publicly on the task force website. One task force member (H.S.) declared that he is a gastroenterologist and performs endoscopy as part of his clinical practice; he participated as a nonvoting member of the working group. All other task force members declared that they had no competing interests for this guideline.

Clinical and content experts are required to disclose any competing interests at the outset of their participation and annually thereafter. One expert declared a conflict in relation to research that was partially supported by industry funds. As per the task force procedure manual, the task force leadership reviewed this declaration. It was determined that the declared conflict was unrelated to the present guideline and would not be expected to have an impact on the transparency, integrity and acceptability of the guideline.

\section{Implementation}

Clinicians should be aware of alarm symptoms for esophageal adenocarcinoma and evaluate, refer and manage patients accordingly. They should also apply clinical judgment for the investigation and management of those unresponsive to GERD treatment or with symptoms suggestive of other upper gastrointestinal disorders (e.g., dyspepsia).

\section{Monitoring and evaluation}

Clinician awareness is an indicator of recommendation uptake. Rates of screening endoscopy could also be monitored to determine adherence. The task force will monitor new evidence and update the recommendation if data become available that could influence its direction or strength. 


\section{Other guidelines}

The Canadian Association of Gastroenterology, British Society of Gastroenterology and American Gastroenterological Association all recommend against routine screening among unselected patients with chronic GERD. ${ }^{4,59,60}$ Some guidelines ${ }^{4,5,60-62}$ suggest screening among patients with GERD who have multiple risk factors (Table 3). These recommendations are not based on screening studies but instead use epidemiological data showing a correlation between specific risk factors (e.g., older age [ $\geq 50 \mathrm{yr}$, male sex, abdominal obesity) and the development of Barrett esophagus or esophageal adenocarcinoma. ${ }^{4-10}$ Some guidelines have also incorporated economic modelling studies $5,62,63$ or expert opinion ${ }^{4}$ in addition to risk factor analysis. Additionally, studies of cohorts with Barrett esophagus show that surveillance may provide a small survival benefit. ${ }^{64-69}$ However, this benefit might be predominantly the effect of lead-time bias; we excluded patients with a previous diagnosis of Barrett esophagus from our guideline.

Table 3: National and international recommendations on screening for esophageal adenocarcinoma, Barrett esophagus or dysplasia

\section{Guideline group}

Canadian Task Force for Preventive Health

Care, 2020

Benign Barrett's and CAncer Taskforce "BoB CAT" consensus group, $2015^{20}$

American College of Gastroenterology, $2015^{5}$

American Society for Gastrointestinal Endoscopy, $2015^{62}$

National Institute for Health Care Excellence, $2014^{61}$

British Society of Gastroenterology, $2013^{4}$

American Gastroenterological Association, $2011^{60}$

Canadian Association of Gastroenterology, $2004^{59}$

\section{Recommendations}

The task force recommends not screening adults with chronic GERD for esophageal adenocarcinoma or precursor conditions (Barrett esophagus or dysplasia) (strong recommendation; very low-certainty evidence).

This guideline suggests against screening the general population for Barrett esophagus endoscopically or with nonendoscopic methods (conditional recommendation, low-quality evidence).

Screening of the general population is not recommended (conditional recommendation, low level of evidence).

Screening for Barrett esophagus may be considered in men with chronic ( $>5 \mathrm{yr}$ ) or frequent (weekly or more) symptoms of gastroesophageal reflux disease and 2 or more risk factors for Barrett esophagus or esophageal adenocarcinoma† (strong recommendation, moderate level of evidence). Screening for Barrett esophagus in women is not recommended. However, screening could be considered in individual cases as determined by the presence of multiple risk factors for Barrett esophagus or esophageal adenocarcinomał (strong recommendation, low level of evidence).

This guideline recommends esophagogastroduodenoscopy for patients who have symptoms suggesting complicated gastroesophageal reflux disease or alarm symptoms§ (moderate-quality evidence). The guideline suggests that endoscopy be considered in patients with multiple risk factors $₫$ for Barrett esophagus (very low-quality evidence).

Endoscopy should not routinely be offered to diagnose Barrett esophagus, but considered if the person has gastroesophageal reflux disease. The recommendation is to discuss the person's preferences and their individual risk factors (for example, long duration of symptoms, increased frequency of symptoms, previous esophagitis, previous hiatus hernia, esophageal stricture or esophageal ulcers, or male gender).

Screening with endoscopy is not feasible or justified for an unselected population with gastroesophageal reflux symptoms (recommendation grade B).

Endoscopic screening can be considered in patients with chronic gastroesophageal reflux disease symptoms and multiple risk factors (at least 3 of the following: age $\geq 50 \mathrm{yr}$, white race, male sex, obesity). However, the threshold of multiple risk factors should be lowered in the presence of family history including at least 1 first-degree relative with Barrett or esophageal adenocarcinoma (recommendation grade $\mathrm{C}$ ).

The guideline recommends against screening the general population with gastroesophageal reflux disease for Barrett esophagus (strong recommendation, low-quality evidence).

In patients with multiple risk factors associated with esophageal adenocarcinoma (age $\geq 50 \mathrm{yr}$, male sex, white race, chronic gastroesophageal reflux disease, hiatal hernia, elevated BMI and intra-abdominal distribution of body fat), the guideline suggests screening for Barrett esophagus (weak recommendation, moderate-quality evidence).

Endoscopic screening for Barrett esophagus in patients with long-standing gastroesophageal reflux disease has not been shown to reduce mortality from esophageal adenocarcinoma (level III evidence, recommendation grade $\mathrm{C}$ ).

Note: $\mathrm{BMI}=$ body mass index, GERD = gastroesophageal reflux disease, WHR = waist-hip ratio.

*International systematic evidence base group endorsed by International Society of Diseases of the Esophagus, Esophageal Charity Fund of Ireland, Fight Esophageal Reflux Together, Association of Upper GI Surgeons, British Society of Gastroenterology, German Gastroenterology Society, American Gastroenterology Association, American College of

Gastroenterology, International Working Group for Columnar Esophagus, European Society of Thoracic Surgeons (www.isde.net/bobcat).

$\dagger$ These risk factors include age $>50$ years, white race, presence of central obesity (waist circumference $>102 \mathrm{~cm}$ or WHR $>0.9$ ), current or history of smoking, and a confirmed family history of Barrett esophagus or esophageal adenocarcinoma (in a first-degree relative).

$\ddagger$ Risk factors include age $>50$ years, white race, chronic or frequent gastroesophageal reflux disease, central obesity: waist circumference $>88 \mathrm{~cm}$, WHR $>0.8$, current or history of smoking, and a confirmed family history of Barrett esophagus or esophageal adenocarcinoma (in a first-degree relative)) (strong recommendation, low level of evidence). $\S$ Alarm symptoms: Dysphagia, odynophagia, weight loss, bleeding or anemia.

ARisk factors include white race, male sex, older age ( $>50$ years of age), prolonged gastroesophageal reflux disease symptoms ( $>5$ years), a family history of Barrett esophagus or adenocarcinoma of the esophagus, nocturnal reflux symptoms, hiatal hernia, increased BMI $\left(\geq 25 \mathrm{~kg} / \mathrm{m}^{2}\right)$, tobacco use and intra-abdominal distribution of fat. 


\section{Gaps in knowledge}

The limited use of a common definition for chronic GERD (i.e., severity, duration, use of medication) reduces the generalizability of existing studies. Ideally, there would be well-designed RCTs examining the effects of screening versus no screening among patients with chronic GERD. Barriers to feasibility, however, include the low prevalence of esophageal adenocarcinoma and limited probability that patients with GERD will progress to cancer. Research that evaluates less invasive or less resourceintensive screening techniques (e.g., Cytosponge or other swallowed devices) ${ }^{70,71}$ or that clarifies treatment effectiveness is also needed. For example, a recent RCT ( $n=2557)$ found improvement in time to all-cause mortality, esophageal adenocarcinoma or high-grade dysplasia for Barrett esophagus treated with combination high-dose proton pump inhibitors and acetylsalicylic acid. ${ }^{72}$ However, this RCT did not meet our review inclusion criteria ${ }^{47}$ as it is yet to be included in a systematic review. Newer forms of surgical treatment (e.g., combined endoscopic mucosal resection and radiofrequency ablation, endoscopic submucosal dissection) also need to be assessed.

\section{Conclusion}

The evidence reviewed for this guideline did not identify clinically meaningful benefits from screening for esophageal adenocarcinoma or precursor conditions in adults with chronic GERD. It also did not provide sufficient data within risk factor categories (e.g., older age [ $\geq 50 \mathrm{yr}$, male sex, abdominal obesity) to support modifying our screening recommendation based on these factors, alone or in combination. The task force provides a strong recommendation that clinicians should not offer screening to adults with chronic GERD. This guideline does not apply to people exhibiting alarm symptoms or those given a diagnosis of Barrett esophagus (with or without dysplasia), who should be evaluated, referred and managed accordingly.

\section{References}

1. Canadian Cancer Statistics Advisory Committee. Canadian Cancer Statistics 2019. Toronto: Canadian Cancer Society; 2019.

2. Otterstatter MC, Brierley JD, De P, et al. Esophageal cancer in Canada: trends according to morphology and anatomical location. Can J Gastroenterol 2012;26:723-7.

3. Canadian Cancer Society's Steering Committee. Canadian Cancer Statistics 2010. Toronto: Canadian Cancer Society; 2010.

4. Fitzgerald RC, di Pietro M, Ragunath K, et al. British Society of Gastroenterology guidelines on the diagnosis and management of Barrett's oesophagus. Gut 2014;63:7-42

5. Shaheen NJ, Falk GW, lyer PG, et al.; American College of Gastroenterology. ACG clinical guideline: diagnosis and management of Barrett's esophagus. Am J Gastroenterol 2016;111:30-50.

6. Spechler SJ, Souza RF. Barrett's esophagus. N Engl J Med 2014;371:836-45.

7. Sami SS, Ragunath K, lyer PG. Screening for Barrett's esophagus and esophageal adenocarcinoma: rationale, recent progress, challenges, and future directions. Clin Gastroenterol Hepatol 2015;13:623-34.

8. Lepage C, Drouillard A, Jouve J, et al. Epidemiology and risk factors for oesophageal adenocarcinoma. Dig Liver Dis 2013;45:625-9.

9. Rubenstein JH. Risk factors for Barrett's esophagus. Curr Opin Gastroenterol 2014;30:408-14.
10. Runge TM, Abrams JA, Shaheen NJ. Epidemiology of Barrett's esophagus and esophageal adenocarcinoma. Gastroenterol Clin North Am 2015;44: 203-31.

11. Vakil N, van Zanten SV, Kahrilas P, et al.; Global Consensus Group. The Montreal definition and classification of gastroesophageal reflux disease: a global evidencebased consensus. Am J Gastroenterol 2006;101:1900-20.

12. Moayyedi PM, Lacy BE, Andrews CN, et al. ACG and CAG clinical guideline: management of dyspepsia. Am J Gastroenterol 2017;112:1484.

13. Dent J, El-Serag HB, Wallander M, et al. Epidemiology of gastro-oesophageal reflux disease: a systematic review. Gut 2005;54:710-7.

14. Fedorak RN, Veldhuyzen van Zanten S, Bridges R. Canadian Digestive Health Foundation Public Impact Series: gastroesophageal reflux disease in Canada: incidence, prevalence, and direct and indirect economic impact. Can J Gastroenterol 2010;24:431-4.

15. Rubenstein JH, Taylor J. Meta-analysis: the association of oesophageal adenocarcinoma with symptoms of gastro-oesophageal reflux. Aliment Pharmacol Ther 2010;32:1222-7.

16. Jankowski J, Barr H, Wang K, et al. Diagnosis and management of Barrett's oesophagus. BMJ 2010;341:c4551.

17. Rubenstein JH, Scheiman JM, Sadeghi S, et al. Esophageal adenocarcinoma incidence in individuals with gastroesophageal reflux: synthesis and estimates from population studies. Am J Gastroenterol 2011;106:254-60.

18. Shaheen NJ, Weinberg D, Denberg T, et al. Upper endoscopy for gastroesophageal reflux disease: best practice advice from the clinical guidelines committee of the American College of Physicians. Ann Intern Med 2012;157: 808-16.

19. Reid BJ, Li X, Galipeau PC, et al. Barrett's oesophagus and oesophageal adenocarcinoma: time for a new synthesis. Nat Rev Cancer 2010;10:87-101.

20. Bennett C, Moayyedi P, Corley DA, et al. BOB CAT: a large-scale review and Delphi Consensus for management of Barrett's esophagus with no dysplasia, indefinite for, or low-grade dysplasia. Am J Gastroenterol 2015;110:662-82.

21. McQuaid KR, Laine L, Fennerty M, et al. Systematic review: the role of bile acids in the pathogenesis of gastro-oesophageal reflux disease and related neoplasia. Aliment Pharmacol Ther 2011;34:146-65.

22. Wani S, Rubenstein JH, Vieth M, et al. Diagnosis and management of low-grade dysplasia in Barrett's esophagus: expert review from the Clinical Practice Updates Committee of the American Gastroenterological Association. Gastroenterology 2016;151:822-35.

23. Peters CJ, Fitzgerald R. Systematic review: the application of molecular pathogenesis to prevention and treatment of oesophageal adenocarcinoma. Aliment Pharmacol Ther 2007;25:1253-69.

24. Desai TK, Krishnan K, Samala N, et al. The incidence of oesophageal adenocarcinoma in non-dysplastic Barrett's oesophagus: a meta-analysis. Gut 2012; 61:970-6.

25. Spechler SJ. Barrett esophagus and risk of esophageal cancer: a clinical review. JAMA 2013;310:627-36.

26. Singh S, Manickam P, Amin A, et al. Incidence of esophageal adenocarcinoma in Barrett's esophagus with low-grade dysplasia: a systematic review and meta-analysis. Gastrointest Endosc 2014;79:897-909.e4.

27. Hippisley-Cox J, Coupland C. Identifying patients with suspected gastrooesophageal cancer in primary care: derivation and validation of an algorithm. Br J Gen Pract 2011;61:e707-14.

28. Canadian Cancer Statistics Advisory Committee. Canadian Cancer Statistics 2018. Toronto: Canadian Cancer Society; 2018.

29. Vaughan TL, Fitzgerald RC. Precision prevention of oesophageal adenocarcinoma. Nat Rev Gastroenterol Hepatol 2015;12:243-8.

30. Atun R. What are the advantages and disadvantages of restructuring a health care system to be more focused on primary care services? Copenhagen: World Health Organization Regional Office for Eurpoe; 2004. Available: www.euro.who.int/_data /assets/pdf_file/0004/74704/E82997.pdf (accessed 2018 Sept. 7).

31. Hamel C, Beck A, Stevens A, et al. Effectiveness of screening for esophageal adenocarcinoma and precancerous conditions (dysplasia and Barrett's esophagus) in patients with chronic gastroesophageal reflux disease with or without other risk factors: protocol for a systematic review. PROSPERO 2017 CRD42017049993. 2017; Available at: www.crd.york.ac.uk/prospero/display_record.php?RecordID $=49993$ and http://canadiantaskforce.ca/guidelines/published-guidelines/ esophageal-adenocarcinoma/. Accessed 2017 Dec. 4. 
32. Hamel C, Beck A, Stevens A, et al. Patient values and preferences in relation to screening for esophageal adenocarcinoma and precancerous conditions (dysplasia and Barrett's esophagus): protocol for a systematic review. 2017; Available at: www.crd.york.ac.uk/prospero/display_record.php?RecordID $=50014$ and http://canadiantaskforce.ca/guidelines/published-guidelines/ esophageal-adenocarcinoma/. Accessed 2017 Dec. 4.

33. Hamel C, Beck A, Thuku M, et al. Screening for esophageal adenocarcinoma and precancerous conditions (dysplasia and Barrett's esophagus) in patients with chronic gastroesophageal reflux disease with or without other risk factors: systematic review. Ottawa: Ottawa Hospital Research Institute; 2018.

34. Hamel C, Beck A, Stevens A, et al. Patient values and preferences in relation to screening for esophageal adenocarcinoma and precancerous conditions (dysplasia and Barrett's esophagus) in patients with chronic gastroesophageal reflux disease with or without other risk factors: Systematic review. Ottawa, Ontario: Ottawa Hospital Research Institute; 2018

35. Hamel C, Ahmadzai N, Beck A, et al. Screening for esophageal adenocarcinoma and precancerous conditions (dysplasia and Barrett's esophagus) in patients with chronic gastroesophageal reflux disease with or without other risk factors: two systematic reviews and one overview of reviews to inform a guideline of the Canadian Task Force on Preventive Health Care (CTFPHC). Syst Rev 2020;9; doi:10.1186/s13643-020-1275-2.

36. Klarenbach S, Sims-Jones N, Lewin G, et al. Recommendations on screening for breast cancer in women aged 40-74 years who are not at increased risk for breast cancer. CMAJ 2018;190:E1441-51.

37. Schünemann H, Brożek J, Guyatt G, et al. GRADE handbook: handbook for grading the quality of evidence and strength of recommendations using the GRADE approach. GRADE Working Group; 2013. Available: http://gdt.guidelinedevelopment. org/app/handbook/handbook.html (accessed 2017 Dec. 4).

38. Andrews JC, Schünemann HJ, Oxman AD, et al. GRADE guidelines: 15. Going from evidence to recommendation-determinants of a recommendation's direction and strength. J Clin Epidemiol 2013;66:726-35

39. Rubenstein JH, Sonnenberg A, Davis J, et al. Effect of a prior endoscopy on outcomes of esophageal adenocarcinoma among United States veterans. Gastrointest Endosc 2008;68:849-55.

40. Hammad TA, Thrift AP, El-Serag HB, et al. Missed opportunities for screening and surveillance of Barrett's esophagus in veterans with esophageal adenocarcinoma. Dig Dis Sci 2019;64:367-72.

41. Chak A, Alashkar BM, Isenberg GA, et al. Comparative acceptability of transnasal esophagoscopy and esophageal capsule esophagoscopy: a randomized, controlled trial in veterans. Gastrointest Endosc 2014;80:774-82.

42. Chang JY, Talley NJ, Locke GR III, et al. Population screening for Barrett esophagus: a prospective randomized pilot study. Mayo Clin Proc 2011;86:1174-80.

43. Sami SS, Dunagan KT, Johnson ML, et al. A randomized comparative effectiveness trial of novel endoscopic techniques and approaches for Barrett's esophagus screening in the community. Am J Gastroenterol 2015;110:148-58.

44. Jobe BA, Hunter JG, Chang EY, et al. Office-based unsedated small-caliber endoscopy is equivalent to conventional sedated endoscopy in screening and surveillance for Barrett's esophagus: a randomized and blinded comparison. Am J Gastroenterol 2006;101:2693-703.

45. Zaman A, Hahn M, Hapke R, et al. A randomized trial of peroral versus transnasal unsedated endoscopy using an ultrathin videoendoscope. Gastrointest Endosc 1999;49:279-84.

46. Mori A, Ohashi N, Yoshida A, et al. Unsedated transnasal ultrathin esophagogastroduodenoscopy may provide better diagnostic performance in gastroesophageal reflux disease. Dis Esophagus 2011;24:92-8.

47. Ahmadzai N, Hamel C, Thuku M, et al. Benefits and harms of treatment options for esophageal adenocarcinoma and precancerous conditions: an overview of systematic reviews. Ottawa: Ottawa Hospital Research Institute; 2018.

48. Lordick F, Mariette C, Haustermans K, et al.; ESMO Guidelines Committee. Oesophageal cancer: ESMO Clinical Practice Guidelines for diagnosis, treatment and follow-up. Ann Oncol 2016;27(Suppl 5):v50-v57.

49. Zaman A, Hapke R, Sahagun G, et al. Unsedated peroral endoscopy with a video ultrathin endoscope: patient acceptance, tolerance, and diagnostic accuracy. Am J Gastroenterol 1998;93:1260-3.

50. Buckland D, Sayal R, Fredrickson K, et al. Patient preferences for esophageal adenocarcinoma screening: data summary. Prepared for the Canadian Task Force on Preventive Health Care. Toronto: Knowledge Translation Program, Li Ka Shing Knowledge Institute, St. Michael's Hospital; 2018.
51. Roth LS, Adams PC. Variation in physician reimbursement for endoscopy across Canada. Can J Gastroenterol 2009;23:503-5.

52. Crott R, Makris N, Barkun A, et al. The cost of an upper gastroduodenal endoscopy: an activity-based approach. Can J Gastroenterol 2002;16:473-82.

53. Paterson WG, Barkun AN, Hopman WM, et al. Wait times for gastroenterology consultation in Canada: the patients' perspective. Can J Gastroenterol 2010;24: 28-32.

54. Leddin D, Armstrong D, Borgaonkar M, et al. The 2012 SAGE wait times program: Survey of Access to GastroEnterology in Canada. Can J Gastroenterol 2013;27: 83-9.

55. Buchman S, Rozmovits L, Glazier R. Equity and practice issues in colorectal cancer screening. Can Fam Physician 2016;62:e186-e193.

56. Ahmed S, Shahid R, Episkenew J. Disparity in cancer prevention and screening in aboriginal populations: recommendations for action. Curr Oncol 2015;22:417-26.

57. Buckland D, Sayal BN, Moore J, et al. Patient preferences in considering esophageal cancer screening outcomes: prepared for the Canadian Task Force on Preventive Health Care. Toronto: Knowledge Translation Program, Li Ka Shing Knowledge Institute, St. Michael's Hospital; 2016.

58. Hamel C, Groulx S, Doull M, et al. Benefits and harms of treatment options fo esophageal adenocarcinoma and precancerous conditions: a protocol for an overview of systematic reviews. PROSPERO 2018 CRD42018084825. London (UK): National Institute for Health Research; 2018. Available: www.crd.york.ac. uk/PROSPERO/display_record.php?ID=CRD42018084825 (accessed 2017 Dec. 4).

59. Armstrong D, Marshall JK, Chiba N, et al. Canadian Consensus Conference on the management of gastroesophageal reflux disease in adults - update 2004 Can J Gastroenterol 2005;19:15-35.

60. Spechler SJ, Sharma P, Souza RF, et al. American Gastroenterological Association medical position statement on the management of Barrett's esophagus. Gastroenterology 2011;140:1084-91.

61. National Institute for Health and Care Excellence (NICE). Dyspepsia and gastrooesophageal reflux disease in adults: quality standard. London (UK): NICE; 2014. Available: www.nice.org.uk/guidance/qs96/resources/dyspepsia-and -gastrooesophageal-reflux-disease-in-adults-pdf-2098972399813 (accessed 2017 June 20).

62. ASGE Standards of Practice Committee; Muthusamy VR, Lightdale JR, Acosta $\mathrm{RD}$, et al. The role of endoscopy in the management of GERD. Gastrointest Endosc 2015;81:1305-10.

63. Whiteman DC, Appleyard M, Bahin FF, et al. Australian clinical practice guidelines for the diagnosis and management of Barrett's esophagus and early esophageal adenocarcinoma. J Gastroenterol Hepatol 2015;30:804-20.

64. Codipilly DC, Chandar AK, Singh S, et al. The effect of endoscopic surveillance in patients with Barrett's esophagus: a systematic review and meta-analysis. Gastroenterology 2018;154:2068-86

65. Wenker TN, Tan MC, Liu Y, et al. Prior diagnosis of Barrett's esophagus is infrequent, but associated with improved esophageal adenocarcinoma survival. Dig Dis Sci 2018;63:3112-9.

66. Fountoulakis A, Zafirellis KD, Dolan K, et al. Effect of surveillance of Barrett's oesophagus on the clinical outcome of oesophageal cancer. Br J Surg 2004;91: 997-1003.

67. Verbeek RE, Leenders M, Ten Kate FJW, et al. Surveillance of Barrett's esophagus and mortality from esophageal adenocarcinoma: a population-based cohort study. Am J Gastroenterol 2014;109:1215-22.

68. Kastelein F, van Olphen S, Steyerberg EW, et al. Surveillance in patients with long segment Barrett's oesophagus: a cost-effectiveness analysis. Gut 2015;64:864-71.

69. Tramontano AC, Sheehan DF, Yeh JM, et al. The impact of a prior diagnosis of Barrett's esophagus on esophageal adenocarcinoma survival. Am J Gastroenterol 2017;112:1256-64.

70. Offman J, Muldrew B, O'Donovan M, et al. Barrett's oESophagus trial 3 (BEST3): study protocol for a randomised controlled trial comparing the Cytosponge-TFF3 test with usual care to facilitate the diagnosis of oesophageal pre-cancer in primary care patients with chronic acid reflux. BMC Cancer 2018;18:784.

71. Moinova HR, LaFramboise T, Lutterbaugh JD, et al. Identifying DNA methylation biomarkers for non-endoscopic detection of Barrett's esophagus. Sci Trans/ Med 2018 Jan 17;10. pii: eaao5848. doi: 10.1126/scitranslmed.aao5848.

72. Jankowski JAZ, de Caestecker J, Love SB, et al. Esomeprazole and aspirin in Barrett's oesophagus (AspECT): a randomised factorial trial. Lancet 2018; 392:400-8. 
Authors: Stéphane Groulx MD, Heather Limburg MSc, Marion Doull PhD, Scott Klarenbach MD MSc, Harminder Singh MD MPH, Brenda J. Wilson MBChB MSc MRCP, Brett Thombs PhD; for the Canadian Task Force on Preventive Health Care

Competing interests: Harminder Singh declared that he is a gastroenterologist and performs endoscopy as part of his clinical practice. Dr. Singh also reports receiving personal fees from Takeda Canada, Pendopharm and Amgen, outside the submitted work. No other competing interests were declared.

This article has been peer reviewed.

Affiliations: Department of Community Health Sciences (Groulx), University of Sherbrooke, Sherbrooke, Que.; Public Health Agency of Canada (Limburg, Doull), Ottawa, Ont.; Department of Medicine (Klarenbach), University of Alberta, Edmonton, Alta.; Internal Medicine and Community Health Sciences (Singh), University of Manitoba, Winnipeg, Man.; Community Health and Humanities (Wilson), Memorial University, St. John's, Nfld.; Department of Psychiatry (Thombs), Jewish General Hospital and McGill University, Montréal, Que.

Guideline writing group: Stéphane Groulx (voting task force member), Heather Limburg (nonvoting science team member), Marion Doull (nonvoting science team member), Scott Klarenbach (voting task force member), Harminder Singh (nonvoting task force member), Brenda J. Wilson (voting task force member), Brett Thombs (voting task force member)

Collaborating Members of the Canadian Task Force for Preventive Health Care: Ahmed Abou-Setta, Heather Colquhoun, Roland Grad, Michael Kidd, Christina Korownyk, Eddy Lang, John C. LeBlanc, Gabriela A. Lewin (former member), Ainsley Moore, Nav Persaud, Donna L. Reynolds, John J. Riva, Guylène Thériault

Contributors: Stéphane Groulx, Heather Limburg, Marion Doull, Scott Klarenbach, Harminder Singh, Brenda Wilson and Brett Thombs contributed substantially to the study concept and design, interpretation of the evidence and critical revision of the guideline draft. Heather Limburg and Marion Doull provided scientific and logistical support to the writing group. Stéphane Groulx, Scott Klarenbach, Harminder Singh, Brenda Wilson and Brett Thombs drafted the recommendations. Stéphane Groulx, Heather Limburg and Marion Doull drafted the guideline statement. All of the named authors gave final approval of the version of the guideline to be published and agreed to be accountable for all aspects of the work. All collaborating members of the Canadian Task Force on Preventive Health Care (Ahmed Abou-Setta, Heather
Colquhoun, Roland Grad, Michael Kidd, Christina Korownyk, Eddy Lang, John LeBlanc, Gabriela Lewin [former member], Ainsley Moore, Nav Persaud, Donna L. Reynolds, John Riva and Guylène Thériault) also made contributions to the development of the guideline and all gave final approval of the version of the guideline to be published.

Funding: Funding for the Canadian Task Force on Preventive Health Care is provided by the Public Health Agency of Canada. The views of the funding body are not considered by the task force in developing its recommendations. The views expressed in this article are those of the task force and do not necessarily represent those of the Public Health Agency of Canada.

Acknowledgements: The authors thank the Ottawa Health Research Institute (OHRI) Evidence Review and Synthesis Centre team (Candyce Hamel, Andrew Beck, Nadera Ahmadzai, Micere Thuku, Kusala Pussegoda, Adrienne Stevens, Becky Skidmore, Avijit Chatterjee, Donna E. Maziak, Kristopher Dennis, Lise Bjerre, Lorenzo Ferri, Beverley Shea, Brian Hutton, Julian Little and David Moher) for its evidence reviews that supported this guideline; Marc Avey, Susan Courage, Bradley Mitchelmore and Rachel Rodin of the Global Health and Guidelines Division at the Public Health Agency of Canada, who supported the development of the guideline; and the Knowledge Translation Program, Li Ka Shing Knowledge Institute, St. Michael's Hospital for their contributions to patient engagement and knowledge translation work related to this guideline. They also thank Paul J. Belletrutti, University of Calgary, Calgary, Alta. and Laura Targownik, University of Manitoba, Winnipeg, Man., for assisting as clinical or content experts during the development of this guideline. Clinical and content experts who have assisted the task force in the guideline process may or may not agree with the task force recommendations. Additionally, the authors thank peer reviewers and organizational stakeholders who provided feedback on the draft guideline, including David Armstrong, McMaster University, Hamilton, Ont.; Shawn Chirrey, Canadian Cancer Society, Toronto, Ont.; Bruce Greenwald, University of Maryland School of Medicine, Baltimore, Md.; Milli Gupta, University of Calgary, Calgary, Alta.; Prasad G. Iyer, Mayo Clinic, Rochester, Minn.; Edward Kucharski, University of Toronto, Toronto, Ont.; Grigorios Leontiadis, McMaster University, Hamilton, Ont. and Gilles Plourde, Health Canada, Ottawa, Ont.

Disclaimer: Nav Persaud is a member of the CMAJ Editorial Advisory board and was not involved in the editorial decision-making process for this article

Correspondence to: Canadian Task Force on Preventive Health Care, info@canadiantaskforce.ca 